\title{
Las cooperativas no agropecuarias en Pinar del Río. Una aproximación al enfoque de género en su funcionamiento
}

\author{
Orisel Hernández Aguilar* \\ Universidad del Pinar del Río (Cuba)
}

Sumario: I. Introducción. II. Las cooperativas no agropecuarias en Cuba: legislación y práctica. III. Aproximación a los estudios sobre cooperativas en Pinar del Río. IV. Las cooperativas no agropecuarias en Pinar del Río. Especial referencia a su enfoque de género. VI. A modo de conclusiones.

Resumen: Este artículo parte de un examen del estado de la regulación y la práctica jurídica en torno a la figura de las cooperativas no agropecuarias en el Derecho cubano. Seguidamente hace alusión al estado y los enfoques de los estudios sobre cooperativas en la provincia de Pinar del Río, para ir a centrarse en la realización de algunas valoraciones generales en torno al actual desarrollo de las cooperativas no agropecuarias en el municipio Pinar del Río, Cuba, particularmente en lo relativo a cómo estas están realizando el enfoque de género en su funcionamiento.

Palabras clave: cooperativa, género, y Derecho.

Abstract: This article leaves of a exam of the state of the regulation and the juridical practice around the figure of the non agricultural cooperatives in the Cuban Law. Subsequently it makes allusion to the state and the focuses of the studies on cooperative in the province of Pinar del Río, to go to center in the realization of some general valuations around the current development of the non agricultural cooperatives in the municipality of Pinar del Río, Cuba, particularly in the relative thing to how they are carrying out the gender focus in their operation.

Key words: cooperative, gender, and Law.

* Máster en Derecho Constitucional y Administrativo, Profesora de Historia General del Estado y el Derecho y Derecho Romano, Departamento de Derecho, Facultad de Ciencias Sociales y Humanísticas, Universidad de Pinar del Río, Cuba.

E-mail: oriselha@upr.edu.cu 


\section{Introducción}

Las cooperativas no agropecuarias son hoy una institución llena de atractivo en la realidad cubana. Se trata de una figura relativamente nueva y con muchas potencialidades inexploradas por lo que acapara la atención de los académicos de distintas ramas del saber, pero también de la población que tiene un interés creciente en adquirir conocimientos sobre la materia.

Ello ha conllevado a que los espacios de estudio y debate se multipliquen ${ }^{1}$ con lo cual el intercambio al respecto se ha vuelto, felizmente, algo recurrente. No obstante, los buenos augurios que siempre trae aparejado el hecho de que un determinado fenómeno gane adeptos, hay que ser cuidadosos de enfocarse en cada momento en lo que resulta posible y pertinente, con lo cual, ahora mismo, más que teorizar en abstracto es momento de conocer la realidad y proponer sobre la base de la experiencia, a fin de aprovechar los espacios legales creados y optimizar las experiencias en ejecución.

Sobre la base de estos presupuestos este artículo parte de un examen general del estado de la regulación y la práctica jurídica en torno a la figura de las cooperativas no agropecuarias en el Derecho cubano. Seguidamente hace alusión al estado y los enfoques de los estudios sobre cooperativas en la provincia de Pinar del Río, para ir a centrarse en la realización de algunas valoraciones en torno al actual desarrollo de las cooperativas no agropecuarias en el municipio Pinar del Río, Cuba, particularmente en lo relativo a cómo estas están realizando el enfoque de género en su funcionamiento.

\section{Las cooperativas no agropecuarias en Cuba: legislación y práctica}

La presencia de las cooperativas en Cuba, con posterioridad al triunfo de la Revolución, fue un resultado del carácter socialista adoptado por el Estado cubano y cuyo fin va dirigido a superar «...la división de los hombres en poseedores de los medios de producción y

1 En los últimos años se ha celebrado numeroso encuentros para abordar el tema (V. gr.: Taller Internacional Sobre Derecho Cooperativo Cuba-España, 2009; las ediciones del COOPERAT; el Seminario Internacional: "Cultura, Cooperativismo y Desarrollo Local», convocado por la Cátedra de Estudios Canadienses de Pinar del Río, el Centro de Estudios sobre Desarrollo Cooperativo y Comunitario, y el Centro de Estudios de Gerencia, Desarrollo Local y Turismo, todos adscritos a la Universidad de Pinar del Río; el I Encuentro Cuba-España sobre Economía Social y Desarrollo Local, en noviembre de 2014; entre otros que sin plantearse el tema como único y principal, sí lo han incluido en sus programas). 
desposeídos de ellos»². A tal propósito debe contribuir esta forma de propiedad a la par que fomenta «las relaciones personales [que] se basen en la colaboración y ayuda mutua» ${ }^{3}$.

No obstante, la cooperativa en Cuba se limitó desde su regulación constitucional en el artículo $20^{4}$ del magno texto cubano al sector agropecuario, toda vez que esta se identificó como un tipo de propiedad que «...constituye una forma avanzada y eficiente de producción socialista» ${ }^{5}$.

Esta situación comenzó a cambiar a partir de la aprobación de los Lineamientos de la Política Económica y Social del Partido y la Revolución (en lo adelante Lineamientos.), el 18 de abril de 2012, por el VI Congreso del Partido Comunista de $\mathrm{Cuba}^{6}$ como directrices para el perfeccionamiento del modelo socioeconómico cubano para los próximos años, figuran bajo el título de "LAS COOPERATIVAS» cinco puntos, del 25 al 29, que incluyen a estas entidades como parte de un nuevo

\footnotetext{
2 Álvarez Tabío, F.: Comentarios a la Constitución socialista cubana, Ed. Pueblo y Educación, La Habana, 1989, pág. 84.

3 ĺdem

4 «Los agricultores pequeños tienen derecho a asociarse entre sí, en la forma y con
} los requisitos que establece la ley, tanto a los fines de la producción agropecuaria como a los de obtención de créditos y servicios estatales.

Se autoriza la organización de cooperativas de producción agropecuaria en los casos y en la forma que la ley establece. Esta propiedad cooperativa es reconocida por el Estado y constituye una forma avanzada y eficiente de producción socialista.

Las cooperativas de producción agropecuaria administran, poseen usan y disponen de los bienes de su propiedad, de acuerdo con lo establecido en la ley y en sus reglamentos.

Las tierras de las cooperativas no pueden ser embargadas ni gravadas y su propiedad puede ser transferida a otras cooperativas o al Estado, por las causas y según el procedimiento establecido en la ley.

El Estado brinda todo el apoyo posible a esta forma de producción agropecuaria.»

Constitución de la República de Cuba, consultada en http://www.parlamentocubano.cu/index.php?option=com_content\&view=article\&id=1418\&ltemid=83 en fecha 25 de mayo de 2012.

5 Sobre el debate respecto al carácter agrario exclusivo de la cooperativa en Cuba «... las interpretaciones doctrinales al texto constitucional cubano de 1976 habían estado divididas (...) Para algunos «la Constitución reconoce a la cooperativa como una propiedad agraria, sin hacerla extensiva a ningún otro tipo de explotación económica», viéndose así - en la definición constitucional de la cooperativa - un límite para la expansión legal de la figura a otros sectores de la economía; para otros, en cambio, «la enumeración constitucional de las formas de propiedad no es taxativa, por lo cual es factible que la ley establezca la autorización para otras modalidades o posibilidades de la propiedad cooperativa.»

Rodríguez Musa, O: La cooperativa como figura jurídica. Perspectivas constitucionales en Cuba para su aprovechamiento en otros sectores de la economía nacional además del agropecuario, Editorial Dikinson SL., Madrid, 2012, pág. 66.

6 Vid. Lineamientos de la Política Económica y Social del Partido y la Revolución, aprobados el 18 de abril de 2012 en http://www.prensa-latina.cu/Dossiers/LineamientosVICongresoPCC.pdf 
«MODELO DE GESTIÓN ECONÓMICA» con el que el país se propone elevar la productividad del trabajo.

Sobre estas bases se fue trabajado hasta que en fecha 11 de diciembre de 2012, la Gaceta Oficial de la República de Cuba en una edición extraordinaria publicó un conjunto de normas que han constituido, con carácter experimental, el marco jurídico para las cooperativas no agropecuarias. Se trata de dos Decretos-Leyes, un Decreto y dos Resoluciones.

El Decreto-Ley N. ${ }^{\circ} 305$ «De las cooperativas no agropecuarias» se ocupa de sentar «las normas que regulan la constitución, funcionamiento y extinción de cooperativas en sectores no agropecuarios de la economía nacional» ${ }^{7}$.

En su Artículo 2.1 el citado Decreto-Ley reconoce a la cooperativa como «una organización con fines económicos y sociales, que se constituye voluntariamente sobre la base del aporte de bienes y derechos y se sustenta en el trabajo de sus socios» ${ }^{8}$. Esta definición de la naturaleza jurídica ha generado controversia porque resulta imprecisa para determinar exactamente qué régimen legal le confiere el legislador cubano.

Según el Artículo 6 del referido Decreto-Ley ${ }^{9}$ las cooperativas tienen cuatro formas esenciales de creación, las que evidencian que los campos fundamentales en los que se crearán las nuevas cooperativas serán aquellos en los que se desempeñan las personas naturales y los que cubren entidades estatales, claramente, en sectores que no se consideran vitales para el país.

Aun cuando la Disposición Final Sexta del Decreto-Ley N. ${ }^{\circ} 305$ concedió al Consejo de Ministros el plazo de trescientos sesenta (360) días para que dictara el Reglamento para las cooperativas de segundo grado $^{10}$ este aun no ha sido promulgado.

7 Art. 1, Decreto-Ley N. ${ }^{\circ} 305$ «De las cooperativas no agropecuarias», Gaceta Oficial N. 053 Extraordinaria de 11 de diciembre de 2012, MINJUS, La Habana, 2012, pág. 249.

8 Art. 2.1, Decreto-Ley N. 305 «De las cooperativas no agropecuarias», Gaceta Oficial N. 053 Extraordinaria de 11 de diciembre de 2012, MINJUS, La Habana, 2012, pág. 249.

9 "Las cooperativas de primer grado pueden formarse: a) A partir del patrimonio integrado por los aportes dinerarios de personas naturales que deciden voluntariamente asociarse entre sí bajo el régimen de propiedad colectiva. b) Por personas naturales que decidan voluntariamente asociarse entre sí, solo con la finalidad de adquirir conjuntamente insumos y servicios, comercializar productos y servicios, o emprender otras actividades económicas, conservando los socios la propiedad sobre sus bienes. c) A partir de medios de producción del patrimonio estatal, tales como inmuebles y otros, que se decida gestionar de forma cooperativa y para ello puedan cederse estos, por medio del arrendamiento, usufructo $u$ otras formas legales que no impliquen la transmisión de la propiedad. d) Una combinación de las formas anteriores.», Decreto-Ley N. ${ }^{\circ} 305 \ldots$ ob. Cit., pág.250.

10 Decreto-Ley N. ${ }^{\circ} 305 \ldots$ ob. Cit., pág.253 
El Decreto-Ley N. ${ }^{\circ} 306$ «Del régimen especial de seguridad social de los socios de las cooperativas no agropecuarias» como su nombre indica "establece un régimen especial de seguridad social dirigido a la protección de los cooperativistas asociados en cooperativas no agropecuarias» ${ }^{11}$.

El Decreto N. 309 del Consejo de Ministros dispone el «Reglamento de las cooperativas no agropecuarias de primer grado». En el Reglamento se dispone, en su Artículo 14, que «el objeto social de la Cooperativa comprende las producciones, prestación de servicios o la actividad de comercialización, a que se dedicará de acuerdo con lo que se autorice ${ }^{12}$. Con ello quedan limitadas las cooperativas cubanas a la colocación de la producción ${ }^{13}$ y a las cooperativas de trabajo ${ }^{14}$.

La Resolución N. ${ }^{\circ} 570$ del Ministerio de Economía y Planificación pone en vigor el procedimiento de licitación respecto a los bienes de un establecimiento estatal para su gestión por las cooperativas no agropecuarias y la Resolución N. ${ }^{\circ} 427$ del Ministerio de Finanzas y Precios ordena las particularidades relativas a la materia tributaria, precios, normas contables, y mecanismos de financiación. En este último sentido hay que apuntar que las cooperativas se han integrado como un elemento dinamizador de la realidad tributaria local, al ser estas contribuyentes de la Contribución Territorial15, primera figura tributaria afectada directamente en beneficio de las localidades.

Hasta el momento se han constituido en Cuba 341 cooperativas $^{16}$. Los fines fundamentales a los que se han destinados son «comercio,

11 Art. 1, Decreto-Ley N. ${ }^{\circ} 306$ "Del régimen especial de seguridad social de los socios de las cooperativas no agropecuarias», Gaceta Oficial N. ${ }^{\circ} 053$ Extraordinaria de 11 de diciembre de 2012, MINJUS, La Habana, 2012, pág. 254.

12 Decreto N. 309 del Consejo de Ministros que dispone el «Reglamento de las cooperativas no agropecuarias de primer grado». Gaceta Oficial N. ${ }^{\circ} 053$ Extraordinaria de 11 de diciembre de 2012, MINJUS, La Habana, 2012, pág. 263.

13 Agrupan productores y procuran colocar los resultados de sus producciones en las mejores condiciones posibles de precio, regularidad y seguridad.

Vid. Kaplan de Drimer, A. y Drimer, B.: Las cooperativas. Fundamentos - HistoriaDoctrina, Ed. Intercoop, Buenos Aires, 1981, pp. 156 y ss.

14 Reúnen a obreros, técnicos, profesionales, etc. que organizan en común su trabajo, a fin de proporcionarles fuentes de ocupación estables y convenientes.

Vid. Ibidem.

15 Artículo 310. Los sujetos de la Contribución Territorial que realicen sus operaciones en pesos cubanos (CUP) y pesos convertibles (CUC), pagan en ambas monedas de forma proporcional a sus ingresos. Ley No. 113 Del Sistema Tributario. Gaceta Oficial No. 053 Ordinaria de 21 de noviembre de 2012.

16 AIN: "A declarar utilidades 290 cooperativas no agropecuarias en Cuba»(27 de enero de 2015), en Juventud Rebelde, consultado en http://www.juventudrebelde.cu/ cuba/2015-01-27/a-declarar-utilidades-290-cooperativas-no-agropecuarias-en-cuba/, en fecha 8 de abril de 2015 . 
gastronomía y servicios; construcción; transporte; industria y alimentación; y recientemente las ramas de energía y servicios contables» ${ }^{17}$.

Respecto a su funcionamiento, resulta difícil hacer generalizaciones, toda vez que cada una de ellas responde a realidades diferentes y tienen una escasa experiencia en su desarrollo. Por ello se hace imprescindible, en el momento actual, profundizar en los estudios de casos, donde es posible comprender de mejor manera, las dinámicas que se producen en la práctica y las causas de las mismas. Afortunadamente en Pinar del Río, existen espacios calificados para asumir la realización de dichos estudios.

\section{Aproximación a los estudios sobre cooperativas en Pinar del Río}

El interés por los estudios cooperativos en Pinar del Río, particularmente en la Universidad Hermanos Saíz Montes de Oca, no es algo reciente. Desde 1998 existe en la Facultad de Ciencias Económicas un Centro de Estudios sobre Desarrollo Cooperativo y Comunitario (CEDECOM) con el propósito de contribuir al desarrollo de la teoría y práctica del cooperativismo a través de actividades de investigación ${ }^{18}$, formación ${ }^{19}$ y asesoría 20 .

17 Rodríguez Delis, L: «Cooperativas no agropecuarias: de una experiencia a una novedad en Cuba», en Granma, 30 de abril de 2014. Consultado en http://www.granma. cu/cuba/2014-05-19/cooperativas-no-agropecuarias-de-una-experiencia-a-una-novedaden-cuba, en fecha 18 de marzo de 2015.

18 Sus proyectos actuales son: El Balance y la Auditoría Social en las CPA y UBPC; La Auditoria Social en las Cooperativas de Producción Agropecuaria y Unidades Básicas de Producción Cooperativa; Estrategia de formación y capacitación de las UBPC en la Provincia Pinar del Río; y Perfeccionamiento de la gestión económica y social de la Empresa de Suministros Agropecuarios de Pinar del Río.

Según http://cedecom.upr.edu.cu/, consultado en fecha 16 de marzo de 2015.

19 Entre las actividades de formación que desarrolla se encuentran los diplomados: Diplomado en Administración y Cooperativismo. Diplomado en Educación, Cooperativismo y Administración. Diplomado en Investigación y Elaboración de Proyectos. Diplomado en Gerencia de Empresas Cooperativas. Diplomado en Gestión y Responsabilidad Social en Cooperativas. Diplomado en Auditoria Social.

Además tienen un programa de Doctorado Curricular Colaborativo en Ciencias Económicas y Administrativas.

Según http://cedecom.upr.edu.cu/, consultado en fecha 16 de marzo de 2015.

20 En su sitio web reflejan como sus objetivos actuales:

- Realizar investigaciones con alto grado de integralidad, objetividad e impacto, con la activa participación de estudiantes de diferentes especialidades, contribuyendo al desarrollo local, en correspondencia con la política científica del MES y las exigencias para la actualización del modelo económico.

- Sistematizar la Educación Cooperativa en pregrado, postgrado y educación no formal. 
Este Centro se ocupa de desarrollar la teoría y práctica del cooperativismo en Cuba y su inserción en la realidad latinoamericana, de manera que conduzca a la obtención de mayores niveles de eficiencia y eficacia socioeconómica en la gestión de las cooperativas y su contribución a la actualización del modelo económico cubano, así como la autorrealización de los miembros de las comunidades y localidades, a través de actividades de investigación, capacitación, servicios científico-técnicos, con una activa participación de profesores y estudiantes, como sustento de su formación profesional, política e ideológica ${ }^{21}$.

A pesar de que sus miembros y líneas de investigación han estado, fundamentalmente, centrados en aspectos relacionados con los enfoques propios de las ciencias económicas el centro ha incorporado a profesionales de otros perfiles como colaboradores, entre ellos algunos juristas (V.gr.: MSc. Orestes Rodríguez Musa).

El reconocimiento a la labor desarrollada por este equipo de trabajo trasciende las fronteras nacionales siendo así que actualmente ocupa la Presidencia de la Sociedad Provincial y Nacional de Cooperativismo de la Asociación Nacional de Economistas y Contadores de Cuba, así como la Presidencia de la Red Latinoamericana de Cooperativismo.

En el Departamento de Derecho en particular, existe un grupo de profesores vinculados al Proyecto «Bases teóricas para la efectiva expansión jurídica de la cooperativa hacia otros sectores de la economía nacional además del agropecuario» que dirige el profesor Orestes Rodríguez Musa.

En este proyecto se ha trabajado en las aristas constitucionales, civiles, fiscales, y administrativas de la institución cooperativa. Las acciones del mismo no se han restringido a la labor investigativa ${ }^{22}$, espacio en el

- Asesorar a las cooperativas, dotando a las mismas de técnicas de gestión gerencial, perfeccionando el control interno en la utilización de los recursos humanos, materiales y financieros sobre la base de un enfoque de desarrollo local sustentable.

- Brindar metodologías, proyectos y asesoramiento de trabajos comunitarios urbanos y rurales.

- Desarrollar la colaboración nacional e internacional.

Según http://cedecom.upr.edu.cu/, consultado en fecha 16 de marzo de 2015.

21 Según http://cedecom.upr.edu.cu/, consultado en fecha 16 de marzo de 2015.

22 Como parte del proyecto se han defendido Tesis de Grado, se prepara una Tesis Doctoral y se han realizado varias publicaciones, muchas de las cuales figuran en el Boletín Anual de la Asociación Internacional de Derecho Cooperativo, adscrita a la Universidad de Deusto, España. Vid. INFORME DE RESULTADOS DEL PROYECTO «Bases teóricas para la efectiva expansión jurídica de la cooperativa hacia otros sectores de la economía nacional además del agropecuario» En 2013 y 2014. Consultado en Vice-Decanato de Investigación y Posgrado de la Facultad de Ciencias Sociales y Humanísticas, Universidad de Pinar del Río. 
cual ostenta importante resultados, sino que ha expandido su proyección a la docencia de pregrado y posgrado ${ }^{23}$.

A estos grupos enfocados en la temática cooperativa se ha venido a sumar el Equipo Multidisciplinario de Investigaciones Sociales (EMIS) de la Facultad de Ciencias Sociales y Humanísticas, que se propone el desarrollo de investigaciones multidisciplinarias en las áreas de las ciencias sociales y las humanidades, enfocadas principalmente al entendimiento y conocimiento de problemáticas sociales - tanto en el nivel local, como regional y nacional- a partir de perspectivas metodológicas que permitan la convergencia y el diálogo de distintas disciplinas ${ }^{24}$.

Dentro de EMIS se encuentra en ejecución un proyecto, del que participan profesionales y estudiantes de disímiles perfiles de las Ciencias Sociales, enfocado a determinar el impacto social, cultural, jurídico y económico de la inserción de la mujer en las formas de gestión del sector no estatal de la economía en el municipio Pinar del Río ${ }^{25}$. Una línea de trabajo de este proyecto apunta al estudio, en particular, de esta realidad en las cooperativas.

Como resultado de todas estas experiencias se ha comenzado el estudio de las cooperativas no agropecuarias del municipio Pinar del Río, a fin, no sólo de determinar las regularidades de su funcionamiento, sino de hacer valoraciones que sienten las bases para diseñar estrategias de capacitación y/o intervención que permitan perfeccionar la realidad cooperativa existente.

\section{Las cooperativas no agropecuarias en Pinar del Río. Especial referencia a su enfoque de género}

Si se toman en cuenta las estadísticas del país, a pesar de no tener el municipio Pinar del Río, una de las mayores concentraciones de coo-

23 Sobre la experiencia de desarrollada en materia de enseñanza Cfr. HernándeZ Aguilar, O. y Rodríguez Musa, O.: «La enseñanza del derecho de cooperativas dentro del modelo de la educación superior en Cuba. La experiencia en la Universidad de Pinar del Río». En Arnáez ARCE, V. M. (coordinadora): Difusión de los valores y principios cooperativos entre la juventud, Editorial Dykinson, s.l., Madrid, 2015, pág.s 87-100.

24 Documento de constitución de EMIS. Consultado en Vice-Decanato de Investigación y Posgrado de la Facultad de Ciencias Sociales y Humanísticas, Universidad de Pinar del Río.

25 Proyecto El impacto social, cultural, jurídico y económico de la inserción de la mujer en las formas de gestión del sector no estatal de la economía en el municipio Pinar del Río. Consultado en Vice-Decanato de Investigación y Posgrado de la Facultad de Ciencias Sociales y Humanísticas, Universidad de Pinar del Río. 
perativas no agropecuarias, vale señalar que la presencia de ocho (8) de estas «organizaciones» es halagüeño para los defensores de la figura.

A continuación se relacionan las cooperativas no agropecuarias (CNA) en funcionamiento y algunos de sus datos más relevantes.

\section{- Café Pinar.}

- Fecha de constitución: 5 de mayo de 2014.

- Forma de constitución: según el inciso d) del Artículo 626 en relación con el 12.2 b) ${ }^{27}$, Decreto-Ley 305.

- Objeto social: prestar servicios gastronómicos, arrendar local y espacios para eventos festivos, según la capacidad y el horario de la instalación, alquiler de espacios para actividades complementarias aprobadas por el arrendador ${ }^{28}$.

- Integración: tiene diez socios, de ellos, ocho son hombres y dos mujeres. Fungen como Presidente de la Asamblea Gene-

26 Artículo 6.-Las cooperativas de primer grado pueden formarse:

a) A partir del patrimonio integrado por los aportes dinerarios de personas naturales que deciden voluntariamente asociarse entre sí bajo el régimen de propiedad colectiva.

b) Por personas naturales que decidan voluntaria-mente asociarse entre sí, solo con la finalidad

de adquirir conjuntamente insumos y servicios, comercializar productos y servicios, o empren-der otras actividades económicas, conservando los socios la propiedad sobre sus bienes.

c) A partir de medios de producción del patrimonio estatal, tales como inmuebles y otros, que se decida gestionar de forma cooperativa y para ello puedan cederse estos, por medio del arrendamiento, usufructo u otras formas legales que no impliquen la transmisión de la propiedad.

d) Una combinación de las formas anteriores.

27 Artículo 12.1. - Los órganos locales del Po-der Popular, organismos o entidades nacionales a que se refiere el artículo anterior presentan a la Comisión Permanente para la Implementación y Desarrollo, las solicitudes de creación de cooperativas, para que dicha Comisión las evalúe y presente al Consejo de Ministros la propuesta de inicio del proceso en las entidades correspondientes.

2. Aprobada la propuesta por el Consejo de Ministros y cumplidos los requisitos establecidos en el Reglamento del presente Decreto-Ley, se dicta la autorización para la constitución de cada cooperativa, atendiendo a las reglas siguientes:

a) en el caso de los incisos a) y b) del artículo 6 del presente Decreto-Ley, por la máxima autoridad del organismo rector de la actividad, oído el parecer de los órganos locales del Poder Popular; y

b) en el supuesto del inciso c) del propio artículo 6, por la máxima autoridad del órgano, organismo o entidad nacional cuyas empresas o unidades presupuestadas administren los bienes, en consulta con el organismo rector cuando corresponda.

28 Escritura Pública de Fundación de Cooperativa no Agropecuaria de Primer Grado. Número: doscientos cuarenta y dos, Pinar del Río, 5 de mayo de 2014. Consultada en el Registro de la Propiedad Mercantil de la Dirección Provincial del Ministerio de Justica en Pinar del Río. 
ral, Administrador, y miembros de la Comisión de Control y Fiscalización socios hombres. Siendo nombradas como Sustituta del Presidente y Secretaria socias mujeres ${ }^{29}$.

- Combinado Industrial de Pinar del Río.

- Fecha de constitución: 26 de septiembre de 2013.

- Forma de constitución: según el inciso d) del Artículo 6 en relación con el 12.2 b), Decreto-Ley 305.

- Objeto social: producir y comercializar muebles y artículos de madera y artesanía variada y prestar servicios de reparación, restauración de muebles e inmuebles de madera, tableros, metal y servicios de pintura de mobiliario tanto en el local de trabajo como en el domicilio de los clientes ${ }^{30}$.

- Integración: tiene dieciocho socios, de ellos, dieciséis son hombres y dos mujeres. Además esta CNA incluye trabajadores contratados, de ellos cuatro son hombres y una es mujer, sin que se especifiquen particularidades al respecto en los acuerdos $^{31}$. Al momento de la constitución de la cooperativa todas las responsabilidades quedaron en manos de los socios hombres.

— Electrónica Hermanos Cruz.

- Fecha de constitución: 17 de septiembre de 2013.

- Forma de constitución: según el inciso d) del Artículo 6 en relación con el 12.2 b), Decreto-Ley 305.

- Objeto social: reparación, mantenimiento y diagnósticos de equipos eléctricos y electrodomésticos; alquiler de equipos a la población, asociado al momento y tiempo de reparación;

29 Esto luego de la Escritura de elevación a públicos de acuerdos sociales de la Cooperativa no Agropecuaria de Primer Grado «Café Pinar». Número cuatrocientos treintaicinco, Pinar del Río, 4 de diciembre de 2014. Consultada en el Registro de la Propiedad Mercantil de la Dirección Provincial del Ministerio de Justica en Pinar del Río.

30 Escritura de Constitución de Cooperativa no Agropecuaria de Primer Grado. Número: setecientos cuarenta y tres, Pinar del Río, 26 de septiembre de 2013. Consultada en el Registro de la Propiedad Mercantil de la Dirección Provincial del Ministerio de Justica en Pinar del Río.

31 Escritura de elevación a públicos de acuerdos sociales de la Cooperativa no Agropecuaria de Primer Grado «Combinado Industrial Pinar del Río». Número quinientos trece, Pinar del Río, 24 de junio de 2014. Consultada en el Registro de la Propiedad Mercantil de la Dirección Provincial del Ministerio de Justica en Pinar del Río. 
realizar reparación ligera a instalaciones eléctricas de viviendas; realizar trabajo de información con las familias sobre el funcionamiento y mejora de equipos 32 .

- Integración: tiene quince socios, de ellos, doce son hombres y tres mujeres. Al momento de la constitución de la cooperativa se acordó nombrar Presidente de la Asamblea General, sustituto del Presidente, y miembros de la Comisión de Control y Fiscalización a socios hombres. Siendo nombrada como Secretaria una mujer.

— Taller de Reparación de Calzado «Estrella Roja».

- Fecha de constitución: 24 de septiembre de 2013.

- Forma de constitución: según el inciso d) del Artículo 6 en relación con el 12.2 b), Decreto-Ley 305.

- Objeto social: reparación de calzado común y ortopédico, reparación de carteras, maletines y otros objetos de este tipo, además lustrado de calzado ${ }^{33}$.

- Integración: tiene catorce socios, de ellos, doce son hombres y dos mujeres. Al momento de la constitución de la cooperativa se acordó nombrar Presidente de la Asamblea General, y miembros de la Comisión de Control y Fiscalización a socios hombres. Siendo nombradas como Sustituta del Presidente y Secretaria socias mujeres.

- Clavel Cooperativa.

- Fecha de constitución: 20 de septiembre de 2013.

- Forma de constitución: según el inciso d) del Artículo 6 en relación con el 12.2 b), Decreto-Ley 305.

- Objeto social: ser un establecimiento gastronómico que se caracteriza por ofrecer un servicio rápido, ofertando productos de lunch y otros productos de fácil elaboración, así como cigarros y tabacos, caracterizándose la instalación por poseer

32 Escritura de Constitución de Cooperativa no Agropecuaria de Primer Grado. Número: trescientos diecinueve, Pinar del Río, 17 de septiembre de 2013. Consultada en el Registro de la Propiedad Mercantil de la Dirección Provincial del Ministerio de Justica en Pinar del Río.

33 Escritura de Constitución de Cooperativa no Agropecuaria de Primer Grado. Número: cuatrocientos cincuenta y tres, Pinar del Río, 24 de septiembre de 2013. Consultada en el Registro de la Propiedad Mercantil de la Dirección Provincial del Ministerio de Justica en Pinar del Río. 
un servicio en mostrador con banquetas (cancha), sistema de autoservicio, con mesas y sillas ${ }^{34}$.

- Integración: tiene catorce socios, de ellos, diez son hombres y cuatro mujeres ${ }^{35}$. Al momento de la constitución de la cooperativa se acordó nombrar Presidente de la Asamblea General, sustituto del Presidente, Administrador, Secretario y miembro de la Comisión de Control y Fiscalización a socios hombres.

- Ornitología Pinar del Río.

- Fecha de constitución: 14 de septiembre de 2013.

- Forma de constitución: no queda claro, debido a la omisión al respecto en todos los documentos consultados ${ }^{36}$, si esta CNA se constituye al amparo del inciso a) o del inciso b) del Artículo 6 en relación con el 12.2 a), Decreto-Ley 305.

- Objeto social: acopiar y comercializar aves ornamentales, producir y comercializar alimentos, jaulas, medicamentos, utensilios y accesorios, además de literatura y medios necesarios para el desarrollo ornitológico, prestación de servicios veterinarios y asesoramiento técnico referente a la actividad ornitológica37.

- Integración: tiene treinta y un socios, de ellos, veinticinco son hombres y seis mujeres. Al momento de la constitución de la cooperativa todas las responsabilidades quedaron en manos de los socios hombres.

34 Escritura Pública de Fundación de Cooperativa no Agropecuaria de Primer Grado. Número: trescientos veinte, Pinar del Río, 20 de septiembre de 2013. Consultada en el Registro de la Propiedad Mercantil de la Dirección Provincial del Ministerio de Justica en Pinar del Río.

35 Escritura de Elevación a Público de Acuerdos Sociales de la Cooperativa no Agropecuaria de Primer Grado «Clavel Cooperativa». Número: cuatrocientos treinta y cuatro, Pinar del Río, 4 de diciembre de 2014. Consultada en el Registro de la Propiedad Mercantil de la Dirección Provincial del Ministerio de Justica en Pinar del Río.

36 Escritura de Constitución de Cooperativa no Agropecuaria de Primer Grado. Número: setecientos siete, Pinar del Río, 14 de septiembre de 2013; Escritura de Elevación a Público de Acuerdos Sociales de la Cooperativa no Agropecuaria de Primer Grado «Cooperativa Ornitológica de Cuba, Pinar del Río». Número: ochenta y uno, Pinar del Río, 30 de enero de 2015; Resolución 583 de 2013 del Ministerio de la Agricultura; Estatutos de las Cooperativa no Agropecuaria «Cooperativa Ornitológica de Cuba, Pinar del Río». Consultados en el Registro de la Propiedad Mercantil de la Dirección Provincial del Ministerio de Justica en Pinar del Río.

37 Escritura de Constitución de Cooperativa no Agropecuaria de Primer Grado. Número: setecientos siete, Pinar del Río, 14 de septiembre de 2013. Consultado en el Registro de la Propiedad Mercantil de la Dirección Provincial del Ministerio de Justica en Pinar del Río. 


\section{— Restaurant Cielo Azul.}

- Fecha de constitución: 19 de septiembre de 2013.

- Forma de constitución: según el inciso d) del Artículo 6 en relación con el 12.2 b), Decreto-Ley 305.

- Objeto social: ofertar una amplia variedad de alimentos elaborados que pueden ser producidos centralizadamente y terminados en la unidad o procesados en el propio establecimiento, donde los usuarios son atendidos en la mesa por personal con la adecuada calificación, lo cual permite combinar la necesidad de alimentación con el disfrute de comodidad; puede incluir platos de la cocina nacional y la oferta puede ser especializada o mixta sobre las bases siguientes: platos para llevar, los que pueden ser envasados y transportados sin pérdida significativa de su calidad ${ }^{38}$.

- Integración: tiene nueve socios, de ellos, cuatro son hombres y cinco mujeres. Al momento de la constitución de la cooperativa se acordó nombrar Presidente de la Asamblea General a un hombre. Siendo nombradas como sustitutas del Presidente, Administradora, y miembro de la Comisión de Control y Fiscalización, socias mujeres.

- Casa Colonial.

- Fecha de constitución: 9 de diciembre de 2013.

- Forma de constitución: según el inciso d) del Artículo 6 en relación con el 12.2 b), Decreto-Ley 305.

- Objeto social: ofertar en el restaurant una amplia variedad de alimentos elaborados que podrán ser producidos centralmente y terminados en la unidad o procesados en el propio establecimiento, en la cafetería alimentos ligeros así como cigarros y tabacos, y en el bar una oferta especializada de bebidos alcohólicas en su estado natural o en coctelería 39.

- Integración: tiene doce socios, de ellos, siete son hombres y cinco mujeres. Al momento de la constitución de la coope-

38 Escritura Pública de Fundación de Cooperativa no Agropecuaria de Primer Grado. Número: trescientos diecinueve, Pinar del Río, 19 de septiembre de 2013. Consultada en el Registro de la Propiedad Mercantil de la Dirección Provincial del Ministerio de Justica en Pinar del Río.

39 Escritura Pública de Fundación de Cooperativa no Agropecuaria de Primer Grado. Número: cuatrocientos ochenta y nueve, Pinar del Río, 9 de diciembre de 2013. Consultada en el Registro de la Propiedad Mercantil de la Dirección Provincial del Ministerio de Justica en Pinar del Río. 
rativa se acordó nombrar Presidente de la Asamblea General, sustituto del Presidente, Administrador y miembro de la Comisión de Control y Fiscalización a socios hombres. Como Secretaria fue electa una socia mujer.

A pesar del poco tiempo que llevan operando estas cooperativas y de la limitada información disponible al respecto, es posible determinar algunos puntos claves relevantes para el enfoque de género. En este sentido conviene valorar la relación sector o actividad de la cooperativa y proporción de socios hombres y mujeres; la contribución al capital inicial de la cooperativa por parte de los socios; la distribución de los cargos cooperativos; los cobros de los anticipos; y el horario laboral.

En cuanto a la relación sector o actividad de la cooperativa y proporción de socios hombres y mujeres se debe partir del reconocimiento de que la mayoría de las cooperativas creadas en Pinar del Río, como se colige de los datos ofrecidos supra, han sido creadas a partir de entidades estatales pre-existentes. De tal suerte, como los antiguos trabajadores han devenido, recientemente, en socios con lo cual esta proporción se ha venido comportando de manera similar a como lo hacía con anterioridad. En el caso de la CNA de Ornitología de Pinar del Río, que sería la única de constitución originaria, esta se desarrolla en un área que ha sido, preponderantemente, de interés y ocupación masculina, lo que explica la escasa presencia femenina en ella.

Al examinar los documentos constitutivos de las cooperativas se aprecia con respecto a la contribución al capital inicial por parte de los socios, una tendencia a la homogeneización de las contribuciones, siendo paritaria para todos los socios ${ }^{40}$ sean estos hombres o mujeres. El único caso que marca la diferencia, la CNA Clavel Cooperativa, la diversidad en las aportaciones no viene explicada ${ }^{41}$. No obstante, de las

40 V. gr. En la CNA Taller de Reparación de Calzado «Estrella Roja» el aporte de cada socio fue de 200 pesos, en la CNA Café Pinar el aporte fue de 500 pesos, en la CNA Casa Colonial fue de 170 pesos, en la CNA Combinado Industrial de Pinar del Río fue de 100 pesos, en la CNA Restaurant Cielo Azul fue de 100 peso, en la CNA Ornitología de Pinar del Río fue de 250 pesos y en la CNA Electrónica Hermanos Cruz fue de 100 pesos.

(Cuando se refiera a pesos cubanos CUP debe tomarse en cuenta que 25 pesos son equivalentes a un peso convertible CUC).

41 Los aportes iniciales son de 500 CUP, 400 CUP, 300 CUP, 200 CUP, 50 CUP y 40 CUP. Escritura Pública de Fundación de Cooperativa no Agropecuaria de Primer Grado. Número: trescientos veinte, Pinar del Río, 20 de septiembre de 2013. Consultada en el Registro de la Propiedad Mercantil de la Dirección Provincial del Ministerio de Justica en Pinar del Río. 
cuatro mujeres socias, dos de ellas son de las que menos capital aportan (una 50 CUP y otra 40 CUP) con lo que queda evidenciado que se les ha dado a estas mujeres un tratamiento diferenciado.

En lo concerniente a la distribución de los cargos cooperativos es evidente la preponderancia de los socios hombres en los cargos de dirección. De hecho no contamos en el municipio con ninguna Presidenta dentro de las ocho cooperativas no agropecuarias. A ello puede estar contribuyendo el hecho de que en casi todas las cooperativas los hombres son mayoría y que en las entidades estatales, que dieron paso a las cooperativas no agropecuarias, los jefes habían sido tradicionalmente personas de sexo masculino. Siendo así no es atribuible a la cooperativa la tendencia a situar, mayoritariamente, hombres en puestos de responsabilidad, sino que es una conducta heredada y sobre la cual, en su desenvolvimiento futuro las CNA aun pueden introducir una pauta propia.

Sobre los cobros de los anticipos lo primero que debe señalarse es que las CNA solo se pronuncian al respecto en sus estatutos ${ }^{42}$. Este documento tiene un carácter casi idéntico para todas las CNA y presenta tal grado de generalización en sus artículos que resulta difícil distinguirlo de una norma jurídica ordinaria. En materia de anticipos mensuales la regla es la abstracción, que impide determinar claramente la voluntad de los socios.

A pesar de esta regularidad, algunas diferencias se han introducido. Nótese que para la CNA Café Pinar el Presidente, el Administrador y los socios deben recibir una remuneración diferenciada, por ello sus estatutos disponen la cuantía exacta a devengar por estos ${ }^{43}$. En la CNA Casa Colonial se toma como referencia para hacer la previsión, la labor que realiza el socio, imitándose el régimen salarial estatal precedente ${ }^{44}$. Por su parte, en la CNA Taller de Reparación de Calzado «Estrella Roja» se introdujo una modificación a los estatutos para precisar los por cien-

42 Al respecto de estos documentos debe señalarse que aparecen con denominaciones dispares V. gr.: Estatutos de la Cooperativa no Agropecuaria de Primer Grado; Acta constitutiva y estatutos de la Cooperativa no Agropecuaria de Primer Grado; Acta constitutiva y proyecto de estatutos de la Cooperativa no Agropecuaria de Primer Grado; y Proyecto de estatutos de la Cooperativa no Agropecuaria de Primer Grado.

43 Artículo 45, Estatutos de la Cooperativa no Agropecuaria de Primer Grado «Café Pinar». Consultados en el Registro de la Propiedad Mercantil de la Dirección Provincial del Ministerio de Justica en Pinar del Río.

44 Artículo 45, Acta constitutiva y estatutos de la Cooperativa no Agropecuaria de Primer Grado. Consultados en el Registro de la Propiedad Mercantil de la Dirección Provincial del Ministerio de Justica en Pinar del Río. 
tos de los ingresos mensuales del mes correspondientes al Presidente, Sustituto del Presidente, Secretario y al resto de los socios ${ }^{45}$.

En este sentido no es posible aducir que haya en exclusiva razón de género para marcar la diferencia en la remuneración percibida. No obstante, de manera indirecta, si se establece un criterio para los anticipos sobre la base de las labores desarrolladas, no podrá marcarse diferencia alguna en este tema, con respecto al sector estatal; y si se prefiere adoptar un criterio que tome como referente las responsabilidades dentro de la cooperativa, las socias mujeres están en desventaja por la misma dinámica de no protagonismo femenino en ellas.

Por último, el horario laboral es otro tópico objeto de una regulación muy general y homogénea. Esto no es consistente con los objetos sociales de la CNA y la forma en que estas funcionan, toda vez que son centros de servicios diversos, unos diurnos y otros nocturnos, por sólo citar un elemento notable a los efectos de la organización del trabajo. Los estatutos, generalmente, disponen que «la duración normal de la jornada laboral será de 8 horas y de un promedio de 44 semanales ${ }^{46}$ y que «se puede establecer una jornada de trabajo irregular cuando por la naturaleza propia del trabajo, por la complejidad de esta o por voluntad de los socios así se acuerde» ${ }^{47}$.

El horario laboral y la posibilidad de flexibilizarlo para atender las necesidades propias de los cooperativistas, en particular las mujeres que simultanean el trabajo con responsabilidades familiares de peso, puede ser una de las aristas más notables para las personas que puedan incorporarse a las mismas, por lo cual resulta llamativa la elección tan convencional hecha en los estatutos.

Estos aspectos, luego de este estudio jurídico-documental inicial, requieren de otros estudios más enfocados en la verificación de su comportamiento dentro de las dinámicas internas de las CNA. Solo así será posible configurar un diagnóstico esencial a fin de instrumentar las alter-

45 Artículo 43, según Escritura de Elevación a Público de Acuerdos Sociales de la Cooperativa no Agropecuaria de Primer Grado. Número: cincuenta y nueve, Pinar del Río, 27 de enero de 2015. Consultada en el Registro de la Propiedad Mercantil de la Dirección Provincial del Ministerio de Justica en Pinar del Río.

46 V. gr. Artículo 12. Acta constitutiva y proyecto de estatutos de la Cooperativa no Agropecuaria de Primer Grado. CNA Taller de Reparación de Calzado «Estrella Roja». Consultada en el Registro de la Propiedad Mercantil de la Dirección Provincial del Ministerio de Justica en Pinar del Río.

47 V. gr. Artículo 13. Acta constitutiva y proyecto de estatutos de la Cooperativa no Agropecuaria de Primer Grado. CNA Taller de Reparación de Calzado «Estrella Roja». Consultada en el Registro de la Propiedad Mercantil de la Dirección Provincial del Ministerio de Justica en Pinar del Río. 
nativas de intervención y capacitación conducentes a perfeccionar el tratamiento a cuestiones de género en las cooperativas no agropecuarias.

\section{A modo de conclusiones}

La legislación experimental para regular las cooperativas no agropecuarias (CNA) en Cuba ha sido objeto de variados estudios, fundamentalmente teóricos y legales. No obstante la relevancia de los mismos, la creación de las CNA y su desarrollo en nuestra realidad van imponiendo la necesidad de, valiéndonos de los antecedentes sentados en materia de estudios cooperativos, avanzar en aquellos que particularicen en la práctica del desarrollo cooperativo, de forma que nos pongan en condiciones para coadyuvar a su perfeccionamiento.

Las cooperativas, incluidas la CNA, suponen un importante espacio de desarrollo de potencialidades en cuanto al enfoque de género, toda vez que están pensadas, desde su esencia, para el mejor desarrollo de sus miembros y de la sociedad en general, por lo cual esta arista, transversal, del fenómeno cooperativista, merece un seguimiento importante dentro del nuevo sector cooperativo.

Las CNA creadas en el municipio de Pinar del Río agrupan a la gran mayoría de las nuevas cooperativas creadas en la provincia como parte de la implementación de los Lineamientos (son 8 de un total de 12). Estas CNA han mantenido lo logrado en el sector estatal en materia de tratamiento de género, pero puede señalárseles que, a pesar de su carácter reciente, podrían hacer, desde ya, una mejor utilización de las alternativas que dicha figura posee para encausar el tratamiento de género.

\section{Bibliografía}

Textos

$\mathrm{ACl}$, «Declaración Sobre la Identidad Cooperativa», Manchester, septiembre de 1995, reproducida y comentada por «EL HOGAR OBRERO: COOPERATIVA DE CONSUMO, EDIFICACIÓN Y CRÉDITO LTDA» en http://www.elhogarobrero1905.org.ar, consultada en diciembre de 2009.

Astelarra, J.: Estado y Políticas de género, publicado en Temas No. 37-38/abrilseptiembre 2004.

Álvarez Tabío, F.: Comentarios a la Constitución socialista cubana, Ed. Pueblo y Educación, La Habana, 1989.

Azcuy, H.: «Análisis de la Constitución cubana», en Revista Papeles de la FIM

No. 14, Madrid, 2000 
CaRAM LeÓn, T.: Empoderamiento femenino en Cuba. Criterios para su análisis en las Cooperativas. FLACSO-Cuba, pág. 1, publicado en http://www.flacso.uh.cu/sitio_revista/num2/articulos/art_TCaram.pdf, consultado en fecha 25 de mayo de 2012.

GadeA, E.; SACRISTÁn, F. y VARgas VAsSerot, C.: Régimen jurídico de la sociedad cooperativa del siglo XXI. Realidad actual y propuestas de reforma, Dykiston SL, Madrid, 2009.

Hernández Aguilar, O. y Rodríguez Musa, O.: "La enseñanza del derecho de cooperativas dentro del modelo de la educación superior en Cuba. La experiencia en la Universidad de Pinar del Río». En Arnáez Arce, V. M. (coordinadora): Difusión de los valores y principios cooperativos entre la juventud, Editorial Dykinson, s.l., Madrid, 2015, pp. 87-100.

Kaplan de Drimer, A. y Drimer, B.: Las cooperativas. Fundamentos - HistoriaDoctrina, Ed. Intercoop, Buenos Aires, 1981.

MAsino, M. A. «Los aportes de Antonio Gramsci para una epistemología materialista del Derecho» publicado en Introducción a la epistemología del Derecho. Dirección de Publicaciones, Universidad Nacional del Rosario, 1988.

Pérez Rolo, Marta y Díaz, Elena: Estudio sobre los valores de dirección y de género en las cooperativas cubanas, Cuaderno pedagógico Volumen 2IRECUS FLACSO/CUBA, Université de Sherbrooke Universidad de La Habana, uniRcoop, 2006.

RodríGuez Musa, O: La cooperativa como figura jurídica. Perspectivas constitucionales en Cuba para su aprovechamiento en otros sectores de la economía nacional diferentes al agropecuario. Dikinson S.L., Madrid, 2011.

VILNITZKY, M. et al.: Mujer y cooperativismo, consultado en http://www.empresaytrabajo.coop/024/dos02401.asp en fecha 27 de abril de 2012.

\section{Otros documentos}

ACTA constitutiva y estatutos de la Cooperativa no Agropecuaria de Primer Grado. Consultados en el Registro de la Propiedad Mercantil de la Dirección Provincial del Ministerio de Justica en Pinar del Río.

ACTA constitutiva y proyecto de estatutos de la Cooperativa no Agropecuaria de Primer Grado. CNA Taller de Reparación de Calzado «Estrella Roja». Consultada en el Registro de la Propiedad Mercantil de la Dirección Provincial del Ministerio de Justica en Pinar del Río.

CUBA: Aprueba consejo de Ministros creación experimental de cooperativas no agropecuarias. Tomado del Noticiero del Mediodía de la Televisión Cubana, publicado en http://www.youtube.com/watch?v=7FVzkQhfkTQ y consultado en fecha 20 de junio de 2012.

DoCUMENTO de constitución de EMIS. Consultado en Vice-Decanato de Investigación y Posgrado de la Facultad de Ciencias Sociales y Humanísticas, Universidad de Pinar del Río.

EL presidente de la Comisión Constitucional de la Asamblea Nacional, José Luis Toledo, explica los Lineamientos, publicado en http://www.parlamen- 
tocubano.cu/index.php?option=com_content\&view=article\&id=3336:elpresidente-de-la-comision-constitucional-de-la-asamblea-nacional-joseluis-toledo-explica-los-lineamientos y consultado en fecha 20 de junio de 2012.

Escritura de Constitución de Cooperativa no Agropecuaria de Primer Grado. Número: setecientos siete, Pinar del Río, 14 de septiembre de 2013. Consultada en el Registro de la Propiedad Mercantil de la Dirección Provincial del Ministerio de Justica en Pinar del Río.

Escritura de Constitución de Cooperativa no Agropecuaria de Primer Grado. Número: trescientos diecinueve, Pinar del Río, 17 de septiembre de 2013. Consultada en el Registro de la Propiedad Mercantil de la Dirección Provincial del Ministerio de Justica en Pinar del Río.

Escritura Pública de Fundación de Cooperativa no Agropecuaria de Primer Grado. Número: trescientos diecinueve, Pinar del Río, 19 de septiembre de 2013. Consultada en el Registro de la Propiedad Mercantil de la Dirección Provincial del Ministerio de Justica en Pinar del Río.

Escritura Pública de Fundación de Cooperativa no Agropecuaria de Primer Grado. Número: trescientos veinte, Pinar del Río, 20 de septiembre de 2013. Consultada en el Registro de la Propiedad Mercantil de la Dirección Provincial del Ministerio de Justica en Pinar del Río.

ESCRITURA de Constitución de Cooperativa no Agropecuaria de Primer Grado. Número: cuatrocientos cincuenta y tres, Pinar del Río, 24 de septiembre de 2013. Consultada en el Registro de la Propiedad Mercantil de la Dirección Provincial del Ministerio de Justica en Pinar del Río.

EsCRITURa de Constitución de Cooperativa no Agropecuaria de Primer Grado. Número: setecientos cuarenta y tres, Pinar del Río, 26 de septiembre de 2013. Consultada en el Registro de la Propiedad Mercantil de la Dirección Provincial del Ministerio de Justica en Pinar del Río.

EsCRITURA Pública de Fundación de Cooperativa no Agropecuaria de Primer Grado. Número: cuatrocientos ochenta y nueve, Pinar del Río, 9 de diciembre de 2013. Consultada en el Registro de la Propiedad Mercantil de la Dirección Provincial del Ministerio de Justica en Pinar del Río.

Escritura Pública de Fundación de Cooperativa no Agropecuaria de Primer Grado. Número: doscientos cuarenta y dos, Pinar del Río, 5 de mayo de 2014. Consultada en el Registro de la Propiedad Mercantil de la Dirección Provincial del Ministerio de Justica en Pinar del Río.

ESCRITURA de elevación a públicos de acuerdos sociales de la Cooperativa no Agropecuaria de Primer Grado "Combinado Industrial Pinar del Río». Número quinientos trece, Pinar del Río, 24 de junio de 2014. Consultada en el Registro de la Propiedad Mercantil de la Dirección Provincial del Ministerio de Justica en Pinar del Río.

Escritura de Elevación a Público de Acuerdos Sociales de la Cooperativa no Agropecuaria de Primer Grado "Clavel Cooperativa». Número: cuatrocientos treinta y cuatro, Pinar del Río, 4 de diciembre de 2014. Consultada en el Registro de la Propiedad Mercantil de la Dirección Provincial del Ministerio de Justica en Pinar del Río. 
EscRITURA de Elevación a Público de Acuerdos Sociales de la Cooperativa no Agropecuaria de Primer Grado "Cooperativa Ornitológica de Cuba, Pinar del Río». Número: ochenta y uno, Pinar del Río, 30 de enero de 2015. Consultada en el Registro de la Propiedad Mercantil de la Dirección Provincial del Ministerio de Justica en Pinar del Río.

Estatutos de las Cooperativa no Agropecuaria «Cooperativa Ornitológica de Cuba, Pinar del Río». Consultados en el Registro de la Propiedad Mercantil de la Dirección Provincial del Ministerio de Justica en Pinar del Río.

Estatutos de la Cooperativa no Agropecuaria de Primer Grado «Café Pinar». Consultados en el Registro de la Propiedad Mercantil de la Dirección Provincial del Ministerio de Justica en Pinar del Río.

INFORME DE RESULTADOS DEL PROYECTO «Bases teóricas para la efectiva expansión jurídica de la cooperativa hacia otros sectores de la economía nacional además del agropecuario» En 2013 y 2014. Consultado en Vice-Decanato de Investigación y Posgrado de la Facultad de Ciencias Sociales y Humanísticas, Universidad de Pinar del Río.

LINEAMIENTOS de la Política Económica y Social del Partido y la Revolución, aprobados el 18 de abril de 2012 en http://www.prensa-latina.cu/Dossiers/LineamientosVICongresoPCC.pdf

NúMERO de cuentapropistas sigue creciendo en Cuba, publicado en http:// www.cubadebate.cu/noticias/2012/04/01/numero-de-cuentapropistas-sigue-creciendo-en-cuba/ y consultado en fecha 20 de junio de 2012.

PROYECTO «El impacto social, cultural, jurídico y económico de la inserción de la mujer en las formas de gestión del sector no estatal de la economía en el municipio Pinar del Río». Consultado en Vice-Decanato de Investigación y Posgrado de la Facultad de Ciencias Sociales y Humanísticas, Universidad de Pinar del Río.

\section{Legislación}

Constitución de la República de Cuba, consultada en http://www.parlamentocubano.cu/index.php?option=com_content\&view=article\&id=1418\&/temi $\mathrm{d}=83$ en fecha 25 de mayo de 2012.

LEY No. 113 Del Sistema Tributario. Gaceta Oficial No. 053 Ordinaria de 21 de noviembre de 2012.

DeCRETo-Ley N. ${ }^{\circ} 305$ "De las cooperativas no agropecuarias», Gaceta Oficial N. 053 Extraordinaria de 11 de diciembre de 2012, MINJUS, La Habana, 2012.

DeCRETO-LEY N. ${ }^{\circ} 306$ «Del régimen especial de seguridad social de los socios de las cooperativas no agropecuarias», Gaceta Oficial N. ${ }^{\circ} 053$ Extraordinaria de 11 de diciembre de 2012, MINJUS, La Habana, 2012.

Decreto N. ${ }^{\circ} 309$ del Consejo de Ministros que dispone el «Reglamento de las cooperativas no agropecuarias de primer grado». Gaceta Oficial N. ${ }^{\circ} 053$ Extraordinaria de 11 de diciembre de 2012, MINJUS, La Habana, 2012. 
Resolución N. ${ }^{\circ} 570$ del Ministerio de Economía y Planificación, Gaceta Oficial N. 053 Extraordinaria de 11 de diciembre de 2012, MINJUS, La Habana, 2012

Resolución N. ${ }^{\circ} 427$ del Ministerio de Finanzas y Precios, Gaceta Oficial N. 053 Extraordinaria de 11 de diciembre de 2012, MINJUS, La Habana, 2012.

Resolución N. ${ }^{\circ} 583$ del Ministerio de la Agricultura de 2013, consultada en el Registro de la Propiedad Mercantil de la Dirección Provincial del Ministerio de Justica en Pinar del Río. 